\title{
Research and Practice of Hybrid Teaching Mode of "Film and Television Production Technology and Art" Course Based on OBE Concept
}

\author{
Yinglong Yu, Tongbao Hao, Hanyue Zhang \\ Southwest Petroleum University, Chengdu, China \\ Email:yyllsz@126.com
}

How to cite this paper: Yu, Y. L., Hao, T. B., \& Zhang, H. Y. (2021). Research and Practice of Hybrid Teaching Mode of "Film and Television Production Technology and Art" Course Based on OBE Concept. Creative Education, 12, 2066-2073. https://doi.org/10.4236/ce.2021.129158

Received: August 20, 2021

Accepted: September 7, 2021

Published: September 10, 2021

Copyright (อ 2021 by author(s) and Scientific Research Publishing Inc. This work is licensed under the Creative Commons Attribution International License (CC BY 4.0).

http://creativecommons.org/licenses/by/4.0/

\begin{abstract}
The OBE education model is a kind of "learning output" oriented education model. In the construction of the course "Film and Television Production Technology and Art", the OBE education concept is effectively integrated with the hybrid teaching mode. The article elaborates this topic from the construction of the teaching model, the effectiveness of the practice, and the matters that need attention in the practice. After practice, it is found that the model can effectively improve the teaching quality of the course and enhance students' independent learning ability and comprehensive application ability.
\end{abstract}

\section{Keywords}

Outcomes-Based Education Mode, Hybrid Teaching Mode, Teaching Mode

\section{Introduction}

The OBE education model is a kind of "learning output" oriented education model. In the construction of the course "Film and Television Production Technology and Art", the OBE education concept is effectively integrated with the hybrid teaching mode. The article elaborates this topic from the construction of the teaching model, the effectiveness of the practice, and the matters that need attention in the practice. After practice, it is found that the model can effectively improve the teaching quality of the course and enhance students' independent learning ability and comprehensive application ability. "OBE" (Outcome Based Education) education, as a modern educational concept, is characterized by the learning output-oriented organization, implementation, and evaluation of edu- 
cational outcomes (Wang et al., 2019). Once basic education reforms appeared and was proposed in North America and Australia in the 1990s, it had received wide attention from the educators. Meanwhile, since the 1990s, this concept has been widely introduced in vocational education in China. It has distinct differences from the traditional teaching model. Specifically, it requires the focus of curriculum design to focus on the final learning outcomes of students, emphasizing that educators must have an extremely clear vision of the competency goals that students can achieve upon graduation and be able to design an educational structure that is suitable for learners to master the knowledge and enhance their competency, helping them achieve the desired outcomes. Furthermore, the strong goal-oriented nature of the OBE education concept also allows it to be widely applied in the field of education.

The blended learning model, having three main features: rich learning resources, support for personalized learning, and high teaching efficiency (Chu, 2017), is a teaching model based on a modern computer network environment, which combines traditional learning methods with online learning (E-learning) (Zou et al., 2019). In the meantime, students can also learn in fragments anytime and anywhere, without the constraints of learning mode and learning time. The teacher changes from the lecturer of knowledge to the organizer and guide of the teaching process. Moreover, the rich online learning resources can strengthen students' motivation in learning and autonomy. Therefore, the OBE education model is very consistent with hybrid teaching in terms of cultivating students' goals. In the teaching of the course teaching "Film and Television Production Technology and Art", we effectively combine the OBE education model with hybrid teaching for teaching practice and reform and have achieved better learning effect.

\section{The Construction of the Hybrid Teaching Mode of the "Film and TV Production Technology and Art" Course Based on the OBE Concept}

\subsection{Clarify the Objectives of Hybrid Teaching of "Film and Television Production Technology and Art" under OBE Education Mode}

According to the objectives of the OBE education concept, we have formulated the main knowledge, ability, and quality objectives of the course. Here, we mainly elaborate on the ability that students should have after learning the course. 1) To be able to master the basic ideas and methods of filming videos (including the use of filming equipment, shot design, scene scheduling, etc.), and to be able to complete a series of shots independently or cooperatively. 2) To be able to master common post-production video editing software, such as Premiere Pro, Finalcut Pro, etc. and can complete different types of film and television editing and post-production creation, independently or cooperatively, and be familiar with the complete post-production editing process, such as editing, sound mixing, color mixing, subtitling, etc. 3 ) Is able to engage in more complex film and 
television production, have better aesthetic and evaluation skills for the produced images, form good learning ability, working ability, and creative thinking ability, develop good professional ethics. All of these are to help lay a solid foundation for future employment.

\subsection{The Construction of Hybrid Teaching Mode Process of "Film and Television Production Technology and Art" under OBE Education Mode}

The teaching mode practice of "Film and Television Production Technology and Art" based on OBE is based on the mainline of learning content, learning results, and audit evaluation, including two forms of learning: online and offline, taking project-based cases as the main implementation carrier, establishing "flexible time and space" independent practice learning mode, creating virtual communities to realize the teaching process "Digital management", the use of "measuring oneself with one's own ruler" to "judge the evaluation" of students' works, and finally using the excellent students' works to participate in disciplinary competitions, apply for open experiment projects. Finally, the outstanding students' works are used to participate in disciplinary competitions, apply for open experimental projects, convert into academic papers, etc. to obtain learning results and gain a sense of learning achievement. The flow chart of the reformed teaching model (Figure 1) is shown in Figure 1.

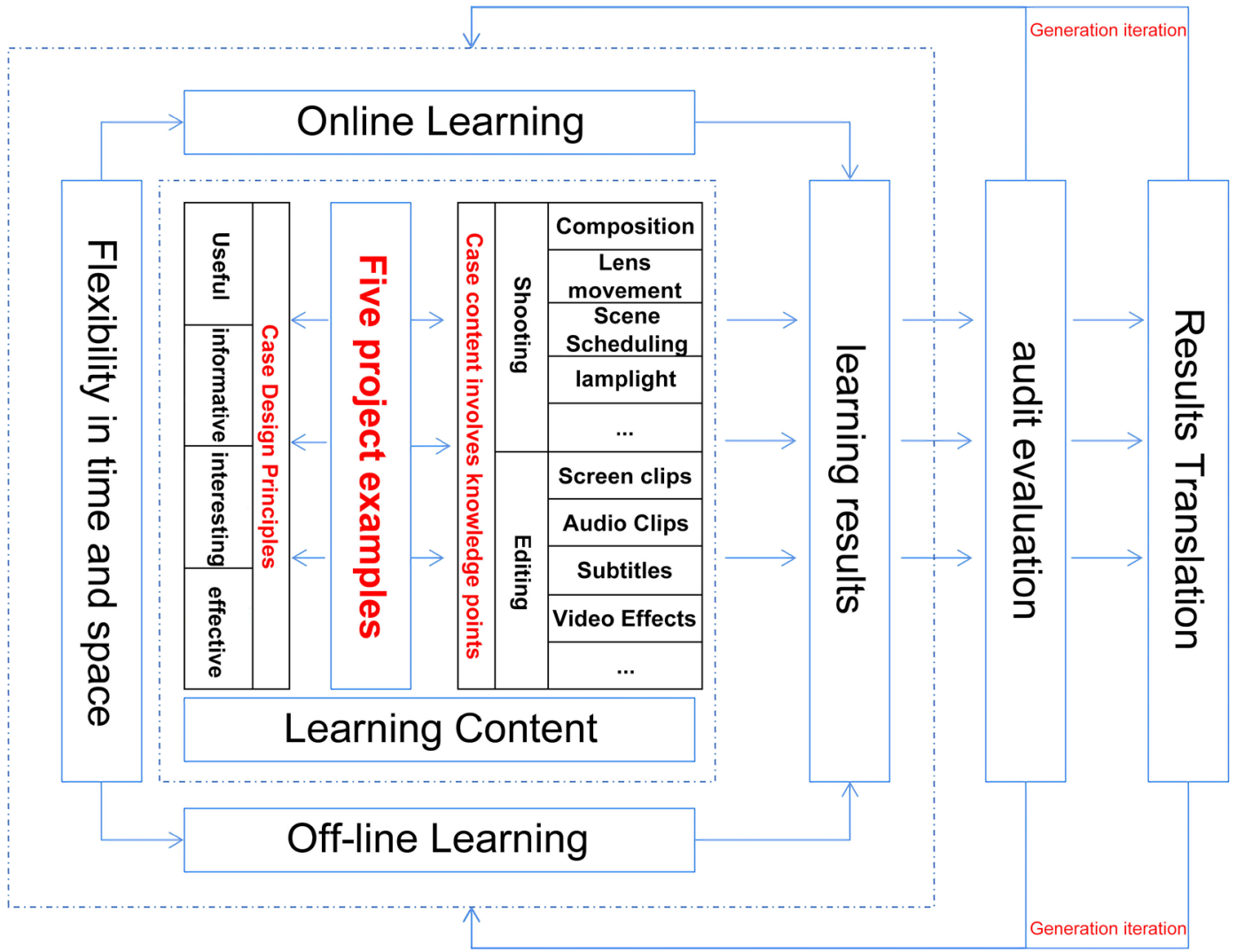

Figure 1. Flow chart of the reformed teaching model. 
1) "Project-based design"- preferred teaching content. According to the textbook and syllabus, all knowledge points and teaching contents are grouped into five major cases. Each case will involve two aspects: pre-shooting and post-editing. Pre-shooting will include a series of compositions, mirroring, scheduling, lighting, and so on, while post-editing will include a series of pictures, sound, subtitles, special effects, etc. The difficulty of the cases ranges from easy to difficult. Meanwhile, the more knowledge points involved in the latter cases, the more comprehensive the ability will be to investigate. At the same time, it should be noted that the design of cases should follow the four principles of useful, informative, interesting, and effective. The teaching content should be studentcentered and specifically designed for students and should start from their actual needs and focus on their participation experience so that they have a sense of integration, interest, and initiative. It should be designed not only for the teacher to teach, but also for the students' "output".

2) "Flexibility in time and space"-flexible forms of learning. Flexible time and space mean that the learners' learning time and space are flexible and changeable, mainly thanks to the hybrid online and offline education model, which makes flexible time and space possible. Flexible time and space include two aspects: flexible time and flexible space. 1) Flexible time. The flexible time refers to the classroom lecture time and the learning time where teachers can intervene before and after the class (mainly including online pre-learning and teacher Q\&A session before the class, and follow-up and Q\&A of the work progress after the class). In the pre-class phase, the teacher gives out project-related knowledge videos and materials on the course platform, and students can pre-study at any time before the class and complete the relevant preliminary test assignments to ensure the completion of the pre-study. In the middle of the class, the teacher divides the class members into teams, and each team makes its own creative design according to the theme of the project. The teacher mainly explains the key points and difficulties of the project case, answers questions, and provides onthe-spot guidance for students to start their projects. It is important to note that the teacher should control the theme determined by each team, and the theme should be as non-repetitive as possible to ensure the richness of the results. The after-school phase is the most flexible part, where students can continue to create their works after school. Although, the teacher needs to regularly monitor the progress and trends on the platform, answer any questions students may have, and provide relevant help in a timely manner. Finally, each team uploads their works to the course platform within the designated time. 2) Flexible Space. The flexible space refers to the richness of learning and practice places. In addition to class time, the classroom computer room is open all day, and students are free to enter the room to create their works when they have no course conflicts. In addition, more professional teacher workshops (except weekends and evenings) are available for students to use to create their works. It is important to note that the open use of these spaces will lead to a significant increase in the workload of the teachers, so a reservation and daily management system should be established 
accordingly to ensure the safety of the students and the equipment, which helps maximize the quantity and quality of the creative output.

3) "Digital management"-innovative management methods. The works of filming and production of film and television not only focus on the innovation of the works, but also on the supervision of the process. Therefore, to ensure the efficiency, the creation process of each project is managed digitally. First, a virtual learning community is created using the cell phone app that accompanies the course center-Learning Pass, through which teachers can lay out project requirements and hand out relevant support materials, etc. Furthermore, through Learning Connect, we are able to collect the learning data of each team and the progress support materials that students need to upload during the creation process, such as script creation process, shot design script, the shooting process, editing clips, etc. This is so that teachers can easily grasp the progress of the students' creation process. The materials submitted by the students are also visible to each group so that they can refer to the work of each other and motivate while also monitor each other, which is an objective and open management.

4) "Audited Evaluation"-Measuring Yourself with Your Own Ruler. A student's final grade consists of the process evaluation score plus the average score of the five works. It is worth mentioning that the method of deriving the scores of students' works is evaluated on an audit-based. Each team sets its own technical indicators before creation, and the teacher evaluates them based on the idea of "measure yourself with your own ruler". In order to enhance fair competition among teams and to stimulate learning from each other, each team participates in the evaluation and scoring of other teams' works, and the final score is obtained by taking a certain weighting ratio between the teacher's and students' scores. The scores among team members are generally the same, which can motivate team members to actively participate in the creation. If there are indeed individual students who are not highly motivated, then the teacher should point that out during the creation process, rather than staggering the grades in the later evaluation. In addition, some process evaluation scores are more objective, such as the scores generated from pre-course previews of watching micro-lessons, scores from course sign-in, class participation activities, and answering questions. So even if the teamwork scores are basically the same, the final total course scores will not be the same.

5) "Promote learning through competition, teaching through competition, and research through competition"-Transformation of project results. At the end of the semester, the course will produce some excellent film and television works, and teachers will encourage and help students participate in various subject competitions, apply for various school-level projects, and even incubate some innovative and entrepreneurial projects, as well as summarize some techniques and experiences in the production process of the works that can contribute to the writing of academic papers or the application of patents. Students not only complete their studies in this process, but also are able to obtain other results, which greatly enhance their self-confidence and sense of accomplishment. The 
conversion of project results is the goal from the very beginning, so the project design should be closely aligned with the competition and research, and in short, to achieve the goal of "promoting learning through competition, teaching through competition, and research through competition".

6) "Project-based iteration"-reverse optimization of the whole teaching process. At the end of each semester, teachers will review the whole course implementation process to find out which parts of the course are problematic that need to be optimized, which parts are very attractive and can be strengthened, and which parts are not connected enough and therefore need to be more interactive. We call this the "project iteration" optimization process. Through iterations over several semesters, the teaching model becomes more mature and the output will be more enriched.

\section{Effectiveness}

1) The comparison of students' performance before and after the practice is shown in Table 1. As demonstrated, the performance of students in 2020 is significantly higher than that in 2019, where all students passed in 2020, and the rate of excellence was also significantly higher.

2) The comparison of students' learning outcomes before and after the reform is shown in Table 2. The number and level of awards for students' works in 2020 are significantly higher than those in 2019 , including 3 awards from provincial subject competitions; the number of projects to which students' works have applied is significantly higher; the number of patents applied for students' works is also significantly higher, and the number of papers or patents converted by students' works is also significantly greater than that in 2019.

\section{Problems to Be Noted in the Reform and Practice of Teaching Mode}

Some problems need to be paid attention to in the whole process of teaching mode reform and practice, such as

1) Students' intimidation. In all stages of the course, there are always some students who are afraid of learning in this course, which will greatly reduce their

Table 1. The comparison of students' performance before and after the practice.

\begin{tabular}{ccccc}
\hline Year & Excellent & Good & Qualified & Unqualified \\
\hline 2020 & $25.6 \%$ & $61.5 \%$ & $12.9 \%$ & 0 \\
2019 & $12.3 \%$ & $40.6 \%$ & $34.7 \%$ & $12.4 \%$ \\
\hline
\end{tabular}

Table 2. The comparison of students' learning outcomes before and after the reform.

\begin{tabular}{cccc}
\hline Year & awards & projects & Papers or patents \\
\hline 2020 & 6 & 4 & 6 \\
2019 & 2 & 1 & 1 \\
\hline
\end{tabular}


enthusiasm to participate in the project and lead to unsatisfactory final results. Thus, it is important for the teacher to observe this potential situation and actively intervene and guide them to help them get through the difficult period so that they can enjoy the process of team creation and collaboration.

2) Students' participation and completion. During the creation process of the project, the division of team members will be clearer, which is good in practice, but for the students, they should try to be proficient in each process of creation and should not be responsible for the same task for all projects. Therefore, teachers should intervene appropriately. For example, although student A is responsible for shooting in project 1 , he or she can also be assigned to different tasks such as editing or lighting in later projects, which is conducive to his or her comprehensive mastery of the course content and helps improve students' willingness to participate and thus the performance.

3) Control and regulation of various kinds of progress.

The most difficult thing to control in the whole teaching mode is the progress of each link. It is relatively easy to control the progress of the pre-course and classroom lectures, but it is more difficult to control the progress of each project. As the project gets more difficult, the more time is left for the students and the more pressure they have to create. If individual groups are unable to submit their work in a timely manner, this can affect the overall progress of the course. This requires a certain amount of documentation and emergency handling on the part of the instructor. Whether assistance is provided in a reasonable and fair manner, or whether the creation time is extended collectively, this will demand flexibility on the part of the instructor, depending on the actual situation.

\section{Research Outlook}

The practical reform of the mixed teaching mode of the "Film and TV Production Technology and Art" course based on the OBE concept has optimized the teaching process, established a perfect mechanism for independent creation of projects, received good results, improved the teaching quality, and reached the reform goal. Moreover, this teaching mode has increased the reliance on the computer room, students' learning enthusiasm, and the affection between teachers and students has deepened. Most importantly, students have gained a lot from the rich teaching and have obtained promising research results, forming a positive learning atmosphere with a virtuous cycle.

\section{Conflicts of Interest}

The authors declare no conflicts of interest regarding the publication of this paper.

\section{References}

Chu, H. Y. (2017). Exploration on the Construction of Practical Training Course System of Local Colleges and Universities in Radio and Television under the Concept of "OBE". 
The Chemistry of Life, 4, 73-75.

Wang, Q. L., Xu, W., Wang, S. H., Feng, W., \& Huang, H. M. (2019). Design and Practical Application of Hybrid Teaching and Learning Based on OBE Education Model "Biochemistry". Chemistry of Life, 39, 1037-1044.

Zou, Y. X., Huang, R., Ma, L. G., Zheng, X. K., Wang, L., Yang, L. H., \& Zhang, L. (2019). The Construction of a Hybrid Teaching Model of Biochemistry in TCM Colleges and Universities. Modern Distance Education in Chinese Traditional Medicine, 17, 157-158. 